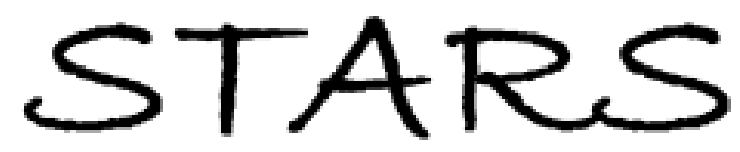

University of Central Florida

STARS

$1-1-2004$

\title{
High conversion efficiency mass-limited Sn-based laser plasma source for extreme ultraviolet lithography
}

\author{
M. Richardson \\ University of Central Florida \\ C. -S. Koay \\ University of Central Florida \\ K. Takenoshita \\ University of Central Florida \\ C. Keyser \\ University of Central Florida
}

M. Al-Rabban

Find similar works at: https://stars.library.ucf.edu/facultybib2000

University of Central Florida Libraries http://library.ucf.edu

This Article; Proceedings Paper is brought to you for free and open access by the Faculty Bibliography at STARS. It has been accepted for inclusion in Faculty Bibliography 2000s by an authorized administrator of STARS. For more information, please contact STARS@ucf.edu.

\section{Recommended Citation}

Richardson, M.; Koay, C. -S.; Takenoshita, K.; Keyser, C.; and Al-Rabban, M., "High conversion efficiency mass-limited Sn-based laser plasma source for extreme ultraviolet lithography" (2004). Faculty Bibliography 2000s. 4740.

https://stars.library.ucf.edu/facultybib2000/4740

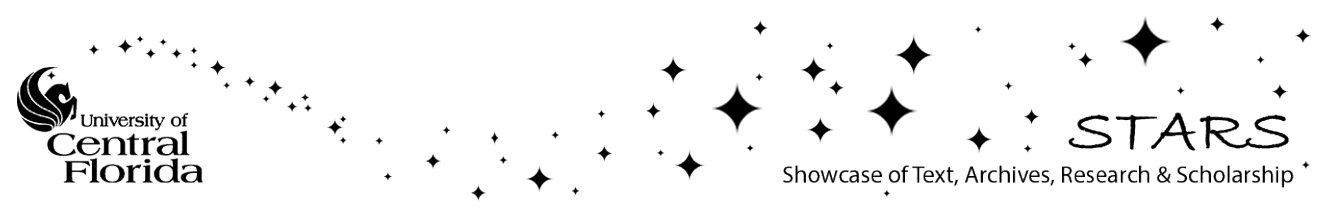




\section{High conversion efficiency mass-limited Sn-based laser plasma source for extreme ultraviolet lithography}

M. Richardson, C.-S. Koay, K. Takenoshita, C. Keyser, and M. Al-Rabban

Citation: Journal of Vacuum Science \& Technology B: Microelectronics and Nanometer Structures Processing, Measurement, and Phenomena 22, 785 (2004); doi: 10.1116/1.1667511

View online: https://doi.org/10.1116/1.1667511

View Table of Contents: https://avs.scitation.org/toc/jvn/22/2

Published by the American Institute of Physics

\section{ARTICLES YOU MAY BE INTERESTED IN}

Extreme ultraviolet lithography

Journal of Vacuum Science \& Technology B: Microelectronics and Nanometer Structures Processing, Measurement, and Phenomena 16, 3142 (1998); https://doi.org/10.1116/1.590453

Extreme ultraviolet lithography: A review Journal of Vacuum Science \& Technology B: Microelectronics and Nanometer Structures Processing, Measurement, and Phenomena 25, 1743 (2007); https://doi.org/10.1116/1.2794048

Plasma physics and radiation hydrodynamics in developing an extreme ultraviolet light source for lithography Physics of Plasmas 15, 056708 (2008); https://doi.org/10.1063/1.2907154

Comparative study on emission characteristics of extreme ultraviolet radiation from $\mathrm{CO}_{2}$ and $\mathrm{Nd}$ : YAG laserproduced tin plasmas

Applied Physics Letters 87, 041503 (2005); https://doi.org/10.1063/1.1989441

Characterization of extreme ultraviolet emission from laser-produced spherical tin plasma generated with multiple laser beams

Applied Physics Letters 86, 051501 (2005); https://doi.org/10.1063/1.1856697

Properties of ion debris emitted from laser-produced mass-limited tin plasmas for extreme ultraviolet light source applications

Applied Physics Letters 87, 241503 (2005); https://doi.org/10.1063/1.2142102 


\title{
High conversion efficiency mass-limited Sn-based laser plasma source for extreme ultraviolet lithography
}

\author{
M. Richardson, ${ }^{\text {a) }}$ C.-S. Koay, K. Takenoshita, and C. Keyser \\ Laser Plasma Lab, School of Optics: CREOL\&FPCE, University of Central Florida, Orlando, \\ Florida 32817 \\ M. Al-Rabban \\ Department of Physics, Qatar University, Doha, Qatar
}

(Received 25 June 2003; accepted 12 January 2004; published 18 March 2004)

\begin{abstract}
Extreme ultraviolet lithography requires a high-efficiency light source at $13 \mathrm{~nm}$ that is free from debris. Our mass-limited Sn-based laser plasma source shows 1.2\% conversion efficiency. Emission spectra from the source were obtained to observe the effects of Sn concentration and effects of laser intensity. Debris measurements were analyzed, and an enhanced repeller field configuration shows marked improvement in mitigating debris. (C) 2004 American Vacuum Society.
\end{abstract}

[DOI: $10.1116 / 1.1667511]$

\section{INTRODUCTION}

Providing a suitable extreme ultraviolet (EUV) point source of sufficient power and longevity is one of the principal challenges facing the development of EUV lithography (EUVL) for fabricating future generation computer chips. ${ }^{1}$ Both discharge and laser plasma sources are being developed to meet this need: a stable, debris-free light source, producing collectable in-band $(2 \%)$ emission at $\sim 13.5 \mathrm{~nm}$ with power levels ${ }^{2}$ of $\sim 100 \mathrm{~W}$. For a laser plasma source to succeed in this application, it must operate continually for periods of $\sim 1 \mathrm{yr}$ at repetition rate of $5-10 \mathrm{kHz}$ with a pulse-topulse stability of $<2 \%$. It must also function so that the large-numerical-aperture $(>0.25)$ collection optics do not suffer from the deleterious effects of target debris in longterm operation. The conversion efficiency from the laser light to useful EUV emission must be sufficiently large to (i) provide the projected required collectable power levels with viable commercial lasers and (ii) permit the overall cost of the source, including the laser, to remain within economic models of the overall EUV lithography stepper tool.

A number of laser plasma sources have been investigated for EUVL, including high-density, pulsed, or continuous cluster targets, ${ }^{3}$ and liquid jets ${ }^{4}$ or droplets ${ }^{5}$ of liquid Xe, which emit broadband radiation (10-14 $\mathrm{nm}$ from $\mathrm{Xe}^{9+}-\mathrm{Xe}^{17+}$ ions), and water $\operatorname{droplet}^{6}$ and jet ${ }^{7}$ targets that radiate narrow line emission from lithium-like oxygen ions. Since 1992, we have been investigating the use of microscopic liquid droplets at a high repetition rate as limitedmass laser plasma targets. ${ }^{6,7}$ Droplet targets have demonstrated extended operating lifetimes without significant debris contamination. ${ }^{8}$ Both approaches showed conversion efficiencies to in-band radiation of $<0.8 \%$ in $2 \pi$ sr, a value that makes achieving the requirement for sufficient power for EUV lithography difficult with the available laser technology.

Here, we report the progress in our studies on a tin material $^{9-11}$ target that demonstrates in-band conversion

${ }^{a)}$ Electronic mail: mrichard@mail.ucf.edu efficiencies in excess of $1 \%$. This will enable $>45 \mathrm{~W}$ (into $2 \pi$ sr within a $2 \%$ spectral bandwidth at $13.5 \mathrm{~nm}$, at the source) of useful EUV source power with current diodepumped Nd:laser technology. ${ }^{12,13}$

\section{EXPERIMENTS AND RESULTS}

To minimize the effects of target debris, we utilize the concept of a limited-mass target. This concept aims towards limiting the mass of the target to one whose mass, and therefore size, approximates that of simply the number of atomic radiators required for emission. In this way, we minimize the number of neutral target atoms generated, and hopefully avoid completely the production of high velocity solid "rocks" or particles emanating from the target. ${ }^{14-16}$ The present target comes in the form of small spherical droplets $\sim 35 \mu \mathrm{m}$ diameter, with each droplet containing about $10^{13}$ tin atoms. These tin-doped droplet targets are produced from a capillary dispenser. When driven through a nozzle driven by a piezoelectric module at a frequency of about $100 \mathrm{kHz}$, a thin chain of droplets is produced (Fig. 1). The stability of

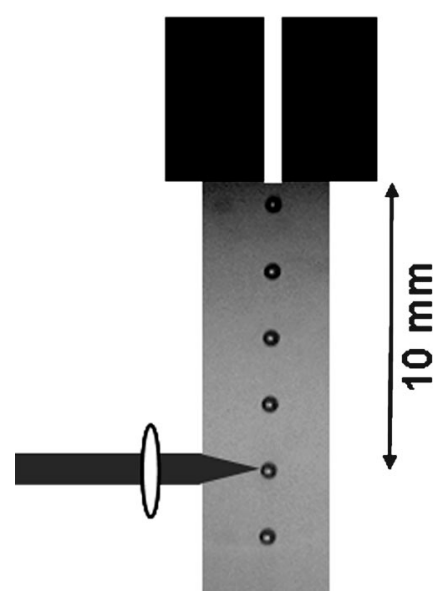

FIG. 1. Thin chain of droplet targets with the laser beam focused on a droplet target. 


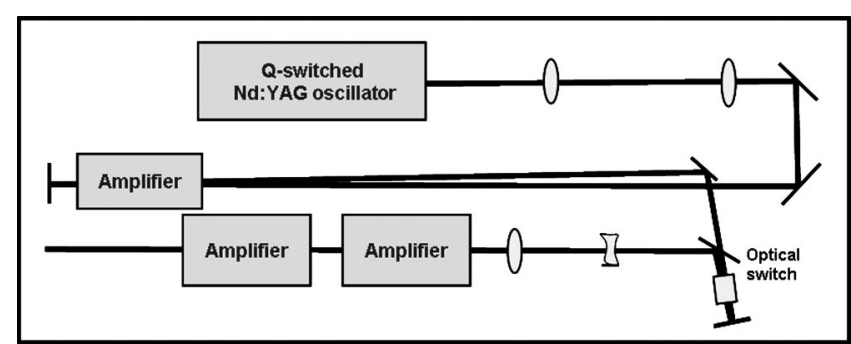

FIG. 2. Schematic diagram of the layout of the precision $1 \mathrm{~Hz}, 10 \mathrm{~ns}, 1.6 \mathrm{~J}$, $\mathrm{Nd}$ :YAG laser used for the experiment showing the master oscillator and three amplifiers.

the high-velocity (typically $2 \times 10^{4} \mathrm{~cm} / \mathrm{s}$ ) droplets in the target region is about $3 \mu \mathrm{m}$ at distances of $\sim 10 \mathrm{~mm}$ from the nozzle exit.

Two lasers were employed in these studies. The first was a special, $Q$-switched Nd:YAG oscillator-amplifier laser system $(\lambda=1064 \mathrm{~nm})$ operating at $1 \mathrm{~Hz}$, producing $1.6 \mathrm{~J}$ per pulse, with a $10 \mathrm{~ns}$ pulse duration. The laser consists of a master oscillator and three amplifier modules (Fig. 2), the final amplifier having an aperture of $10 \mathrm{~mm}$. The resulting output laser beam has an $M^{2}=1.5$, and was focused to a spot size of $80 \mu \mathrm{m}$ with a $5 \mathrm{~cm}$ focal length lens. Figure 3 shows the far-field beam profile and the temporal pulse shape. The second laser was a Spectra Physics Quanta Ray: $100 \mathrm{~Hz}, 300$ $\mathrm{mJ}, 10 \mathrm{~ns} \mathrm{Nd}$ :YAG laser $(\lambda=1064 \mathrm{~nm})$, and was primarily used for multipulse debris measurements.

The experimental setup is shown in Fig. 4. The target was located centrally in a 45 -cm-diam vacuum chamber, which was operated at pressure below $10^{-3}$ Torr with a turbo-drag pump backed with a roughing pump. At this pressure, absorption of EUV radiation by the air inside the target chamber is $<1 \%$ for distance of $\sim 100 \mathrm{~cm}$.

Several EUV diagnostics have been used to analyze the emission spectra and diagnose the expansion of the plasma. High-resolution spectra of the source have been obtained by using a flat-field reflection grating spectrometer (FFS) and a transmission grating spectrometer (TGS). A back-thinned x-ray CCD camera was used to record the dispersed spectrum. The FFS uses a $1200 \mathrm{lpmm}$ variable spaced reflective grating ${ }^{17}$ in a configuration reported previously. ${ }^{18}$ An $80 \mu \mathrm{m}$ slit was used to collimate the light from the source to the grating with a grazing incidence angle of $3^{\circ}$. The slit-tograting and grating-to-image-plane distances were 23.7 and

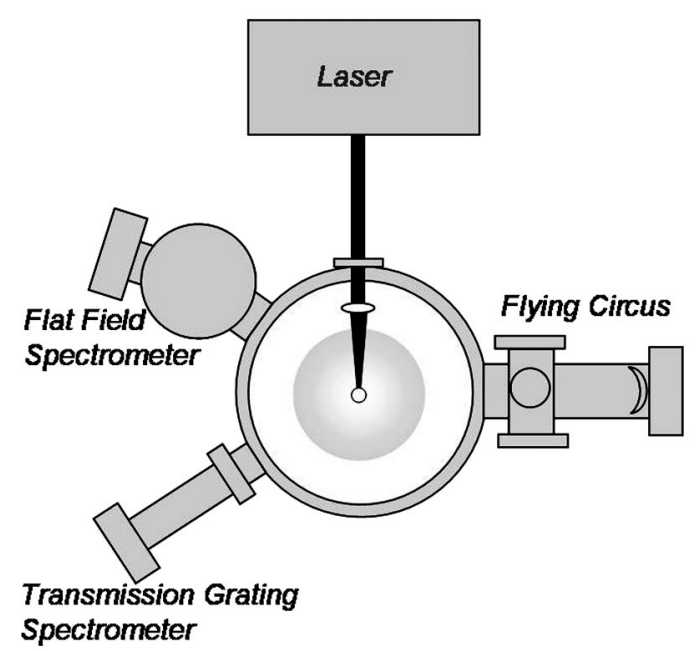

FIG. 4. EUV diagnostics connected to different ports of laser plasma source-target vacuum chamber.

$23.5 \mathrm{~cm}$, respectively. The TGS has a periodicity $5000 \mathrm{lpmm}$. A $100 \mu \mathrm{m}$ slit was placed between the source and the grating at $27 \mathrm{~cm}$ source-to-slit separation. A $0.5-\mu \mathrm{m}$-thick $\mathrm{Zr}$ metal filter was used in each spectrometer to select wavelengths from 6.5 to $16.8 \mathrm{~nm}$ full-width at half-maximum.

The narrowband EUV emission from the source was measured with the so-called Flying Circus ${ }^{19}$ (FC) diagnostic. The $\mathrm{FC}$ is a narrowband EUV diagnostic comprising a calibrated curved normal incidence multilayer mirror (MLM) and a $\mathrm{Zr}$ filtered AXUV-100 photodiode. ${ }^{20}$ The Mo-Si multilayer spherical mirror collects light from the source and has a reflectivity of $58 \%$ in a narrow spectral band $(\sim 3 \%)$. The photodiode has a spectral responsivity of $\sim 0.23 \mathrm{~A} / \mathrm{W}$ at $13.5 \mathrm{~nm}$, and it is reversed bias at $26 \mathrm{~V}$. The $\mathrm{Zr}$ filter is $0.5 \mu \mathrm{m}$ thick with $\sim 18 \%$ transmission for $13.5 \mathrm{~nm}$ radiation.

Using the $100 \mathrm{~Hz}$ laser, a spectrum of emission from the tin material laser plasma source in the $10-19 \mathrm{~nm}$ regions was recorded using the FFS with $20 \mathrm{~s}$ exposure on a $1024 \times 1024$ pixel x-ray CCD camera. ${ }^{21}$ For comparison, a spectrum for the liquid water droplet source was also obtained. Figure 5 compares the EUV spectra for both sources for the same number of laser shots. The spectrum from the water droplet source shows a narrow peak at $\sim 13 \mathrm{~nm}$ corresponding to the $4 d-2 p$ transition from lithium-like oxygen. In comparison, the spectral peak in the $13 \mathrm{~nm}$ region for the tin material
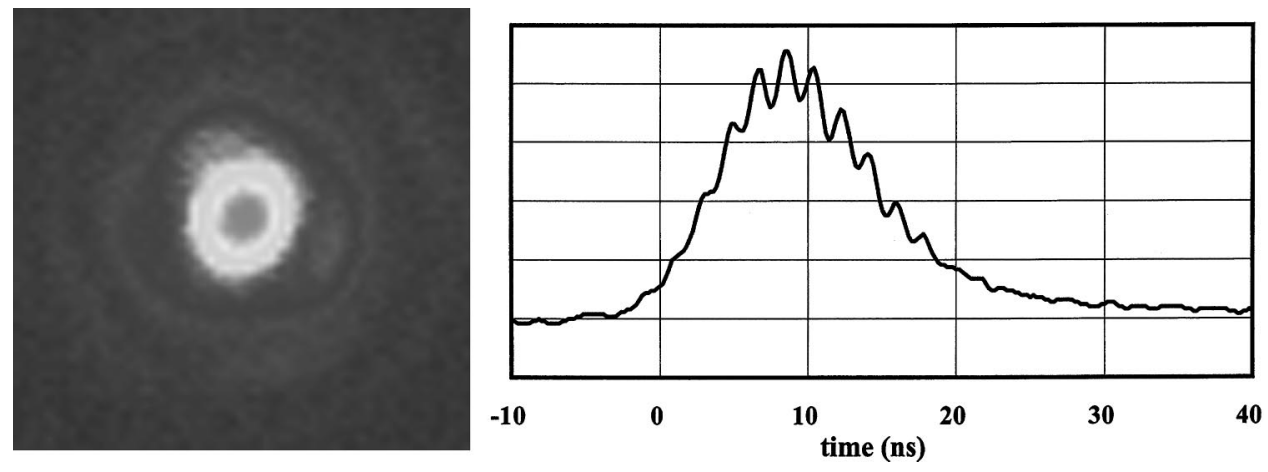

FIG. 3. Laser beam cross section and temporal pulse shape for pulse energy $1.6 \mathrm{~J}$ per pulse. 


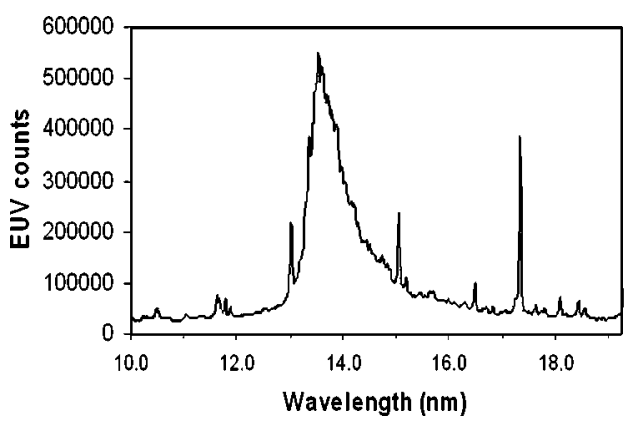

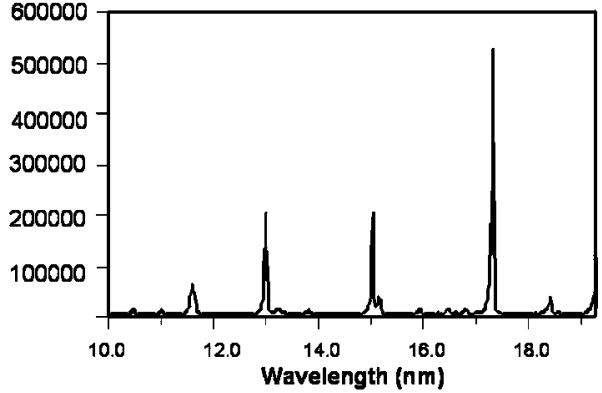

FIG. 5. Comparison of the spectra recorded for tin material droplet source and water droplet source for the same amount of laser shots. source is broader and higher than that of the water droplet source. This enhancement in the $13 \mathrm{~nm}$ emission for tin is made possible by the unresolved transition array $(4 d-4 f$ transitions) from $\mathrm{Sn}^{4+}$ to $\mathrm{Sn}^{13+}$ ions.

Initial studies have also been performed to examine the tin source spectra as a function of the tin concentration in the target and as a function of the laser intensity. These are shown in Figs. 6 and 7. These data were obtained by using the $1 \mathrm{~Hz}$ laser and the FFS, in which the $\mathrm{x}$-ray CCD camera $^{22}$ was exposed for $240 \mathrm{~s}$. For the same laser pulse energy and intensity, the EUV emission increases with increasing tin

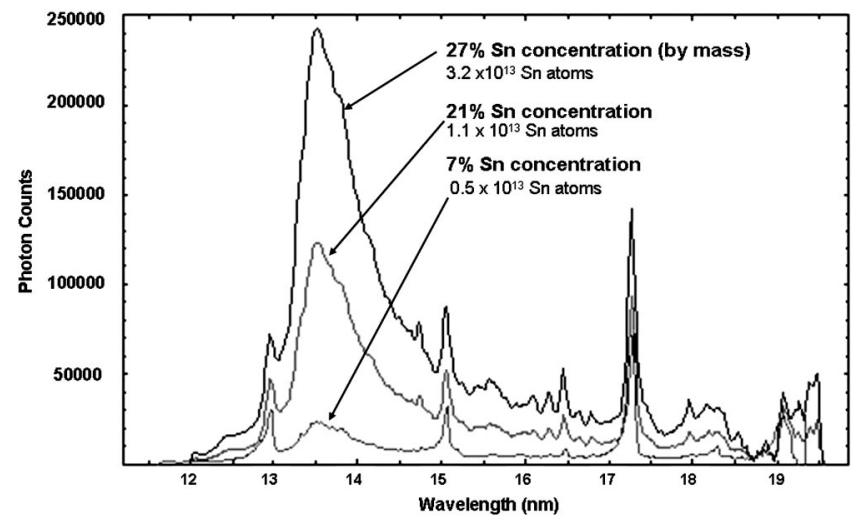

FIG. 6. Comparison of spectra recorded for the tin material source at different values of tin concentration in the target for the same number of laser shots.

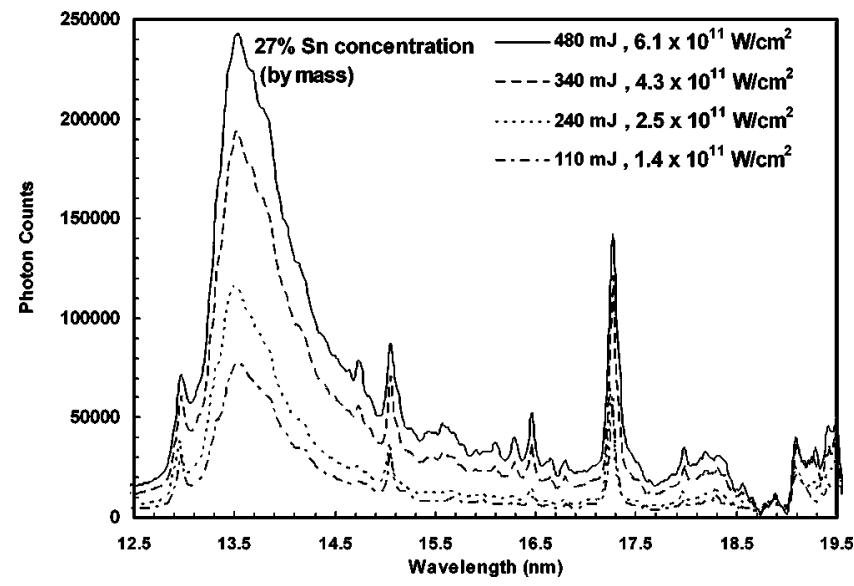

FIG. 7. Comparison of spectra recorded for the tin material source at different values of laser intensity on the target for the same number of laser shots. The tin concentration in the target is $27 \%$ by mass. concentration. In the case of the solid tin target, significant broadening of the EUV peak at $13.5 \mathrm{~nm}$ has been observed ${ }^{23}$ when the tin concentration (by mass) was varied from $1 \%$ to $5 \%$. The spectrum of the EUV radiation at $13.5 \mathrm{~nm}$ from the droplet source, however, remains fairly narrow $(\sim 6.5 \%)$, and does not increase significantly in bandwidth as a function of tin concentration.

The FC was aligned to the plasma source at $60^{\circ}$ with respect to the incident laser beam. The distance from the plasma to the MLM was $\sim 1 \mathrm{~m}$, giving a $600 \mu$ sr collection solid angle. The EUV signal from the AXUV photodiode in the FC was observed with a high-speed oscilloscope. The total EUV energy radiated ${ }^{19}$ in $2 \pi$ sr was determined from

$$
E_{\text {euv }}=\frac{2 \pi A_{\text {scope }}}{\Omega T_{\text {filter }} R_{\text {mirror }} S_{\text {diode }} Z_{\text {scope }}},
$$

where $\Omega$ is the source-to-mirror collection solid angle, $R_{\text {mirror }}$ and $T_{\text {filter }}$ are the mirror reflectivity and metal filter transmission, respectively, $S_{\text {diode }}$ is the spectral responsivity of the AXUV photodiode, and $Z_{\text {scope }}$ is the input impedance at the measurement channel into the oscilloscope. The integrated voltage of the EUV signal observed on the oscilloscope is $A_{\text {scope }}$. This estimate assumes isotropic emission from the source. The conversion efficiency was measured to be $1.2 \%$ when using the $1 \mathrm{~Hz}$ laser with $0.64 \mathrm{~J}$ per pulse. However, this value for the conversion efficiency, is, we believe, not yet fully optimized. Clearly, there are many irradiation and target parameters that need to be collectively optimized. This requires a full characterization of the plasma and radiation dynamics, a study of which is currently underway, aided by detailed code simulations.

\section{PLASMA HYDRODYNAMIC CODE CALCULATION}

The radiation emitted from laser plasma depends strongly on the plasma conditions, such as the electron temperature and electron density. The one-dimensional, time-dependent Lagrangian hydrodynamic code, MEDUSA, ${ }^{24}$ was used to model the plasma dynamics of the tin-doped droplet laser plasma. Typical calculations were made for a target with the following parameters: $10 \%$ tin-doped material, $35-\mu \mathrm{m}$-diam spherical target, $10 \mathrm{~ns}$ laser pulse duration, and 4.5 $\times 10^{11} \mathrm{~W} / \mathrm{cm}^{2}$ laser intensity at the target position. Figure 8 shows the predicted electron temperature and density for a time corresponding to the peak of the laser pulse. These 


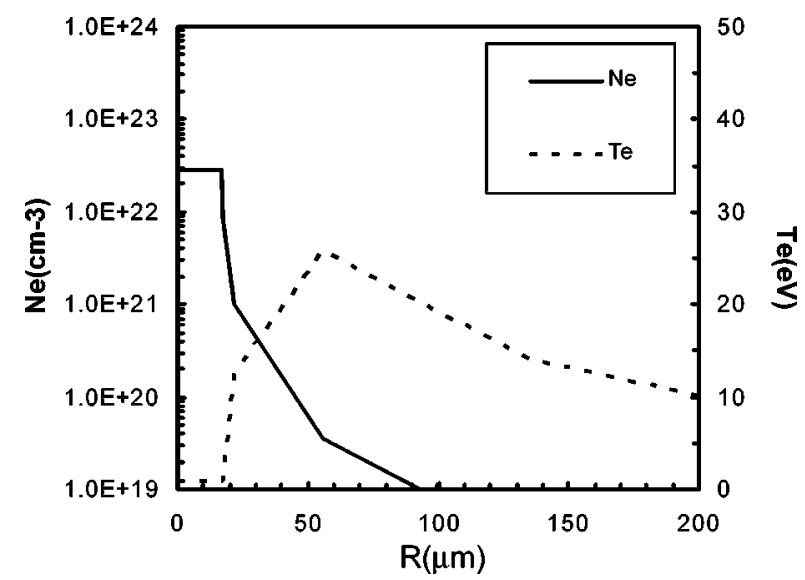

FIG. 8. Plot of electron temperature $\left(T_{e}\right.$ in $\left.\mathrm{eV}\right)$ and electron density $\left(N_{e}\right.$ in $\mathrm{cm}^{-3}$ ), as a function of distance from the center of target for a laser plasma of a tin-doped target material, when the peak of laser pulse coincides with center of target.

simulations show that by the time the laser pulse reaches this peak intensity, the absorption region of the plasma, located at distances from the center of the target that are below the critical density for the laser radiation $\left(\sim 10^{21} \mathrm{~cm}^{-3}\right)$, has expanded to completely fill the laser spot size. Moreover, the maximum temperature predicted is close to that required for optimum ionization and excitation of the $\mathrm{Sn}^{+8}-\mathrm{Sn}^{+11}$ ions that emit most in the $13 \mathrm{~nm}$ region.

\section{DEBRIS STUDIES}

Debris from the plasma source degrades the MLM reflectivity of the condenser optics. The overall lifetime of the combination of the plasma source and MLM optics depends mainly on how long the reflectivity of the first collimator mirror is maintained. It is a critical element in the system. This mirror is in direct line-of-sight to the source and sustains the full impact, not only of radiation outside the passband of its coatings, but also of electrons, ions, neutral atoms, and any particulate matter that originates directly from the target, or indirectly from other surfaces as a consequence of the source. All these factors can degrade the mirror in different ways. For instance, particulate matter, depending on its state and kinetic energy, can coat, chip, and/or indent the surface of the mirror. Ions, on the other hand, will, with sufficient energy, ablate or sputter the coating layers, while oxygen atoms will tend to oxidize the uppermost silicon layer of the mirror, reducing its reflectivity.

As mentioned earlier, our approach to minimizing the effects of debris is through the use of mass-limited targets. Ideally, we then have a source that consists of the absolute minimum number of radiating ions necessary to produce the required power. We have previously made detailed lifetime studies of MLMs exposed to the long-life effects of ions and particles from high-repetition-rate $(100 \mathrm{~Hz})$ laser plasmas created from microscopic water droplet targets. ${ }^{25}$ During this study, we developed several techniques that provide information on the progressive degradation of the mirror. We found, for instance, that scanning electron microscopy analysis of

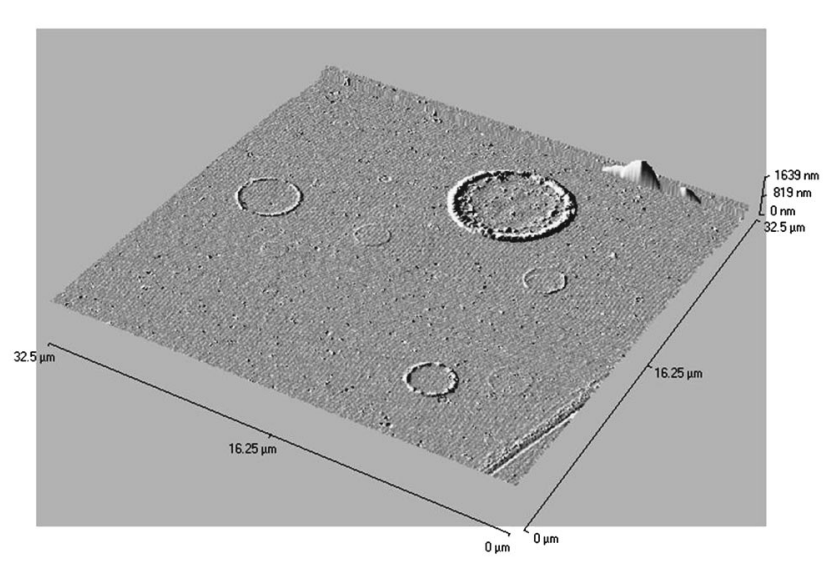

FIG. 9. AFM image of tin deposition on a MLM.

MLMs after this irradiation showed signs of sputtering by oxygen ions. In addition, if we slowed these ions down with a buffer gas, then x-ray photoelectron spectrometry (XPS) of the MLMs indicated oxidation of the mirror occurred. These studies also verified that MLMs sustained no detectable damage from particulate matter such as unionized chunks of material or even clusters when the water-droplet target was used as a source. This early work with water droplet targets also led to the development of the repeller field concept of ion inhibition for debris mitigation. ${ }^{25}$

Witness-plate post-shot (WPPS) analysis techniques as well as measurements of ions are used for debris analysis. The witness-plate post-shot analysis techniques can show the direct result of the degradation caused by debris and the accumulated impact over a certain number of shots. Moreover, WPs can show the impacts caused by not only ions but also particulate matter which may not be charged at the time when the laser pulse interacts with the target. Glass plates (microscope slides) and MLMs are used as WPs in the current experiments. Measurement of ions can tell us about the ion velocity distributions and the species of ions. Charge collectors such as Faraday cup detectors and a Thomson parabola ion spectrometer are appropriate for such measurements.

The initial results from the WPPS analysis techniques are the following. The MLM sample was exposed to the laser plasma source for $2.7 \times 10^{5}$ laser shots at a distance of 75 $\mathrm{mm}$ from the source. An atomic force microscope (AFM) (TA instrument $\mu$ TA-2990) is used to determine the size of each deposit. Typical AFM images are shown in Fig. 9. An area of a $32.5 \mu \mathrm{m}$ square was sampled with 400 resolution setting and sampling rate of $32.5 \mu \mathrm{m} / \mathrm{s}$. Some of the larger deposits appear in the form of rings. By analyzing the crosssectional profile of a deposit, the volume of the deposit can be calculated. The volume of the largest deposit is found to be $7 \times 10^{-13} \mathrm{~cm}^{3}$. Its mass is about $5 \times 10^{-12}$ gram, which is less than $5 \times 10^{-2} \%$ of mass of a single target. The minimum deposit thickness measurable by the AFM is about 2 $\mathrm{nm}$. Identification of the material of the deposit is carried out by using the XPS (Perkin-Elmer PHI 5600) and Auger electron spectroscopy (AES) (Perkin-Elmer PHI 600). In both 
(a)

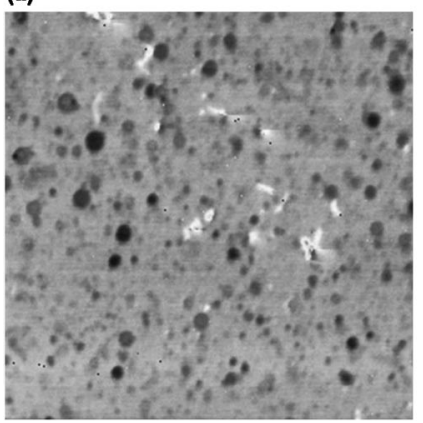

(b)

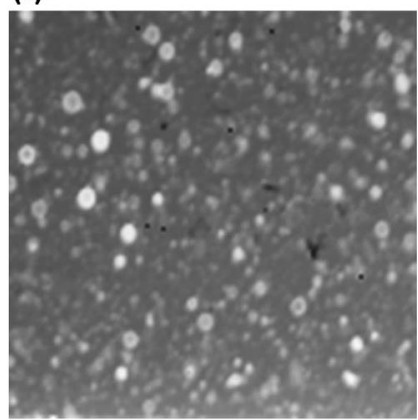

FIG. 10. (a) AEM image $140 \mu \mathrm{m} \times 140 \mu \mathrm{m}$ and (b) backscattered image (same area).

XPS and AES surface analysis, the spectroscopic measurement showed a result indicating tin material in the deposit. By scanning the electron beam across the surface of interest, we obtained a map (image) of material distribution, shown in Fig. 10. The figure shows an Auger electron microscopy (AEM) image and a backscattered image. Both images are taken from the same area of an MLM WP surface. The backscattered image shows the spatial distribution of high- $Z$ material, where the brighter spots are deposits of higher-Z materials. The deposits shown in the AEM image completely overlap the bright deposits on the backscattered image. Since no signal of molybdenum was detected, all the deposits have to be tin.

\section{A MORE ADVANCED REPELLER FIELD CONFIGURATION}

The repeller field approach to debris mitigation was first applied to the water droplet target. ${ }^{25,26}$ In these early studies, we found that ion sputtering on the surface of the MLM was the cause for the drop of reflectivity of the mirror with progressive exposure to the source. The installation of a repeller electrostatic field between the source and the MLM reduced the ion flow considerably, resulting in extended life of the mirror by at least a factor of $\sim 10$.

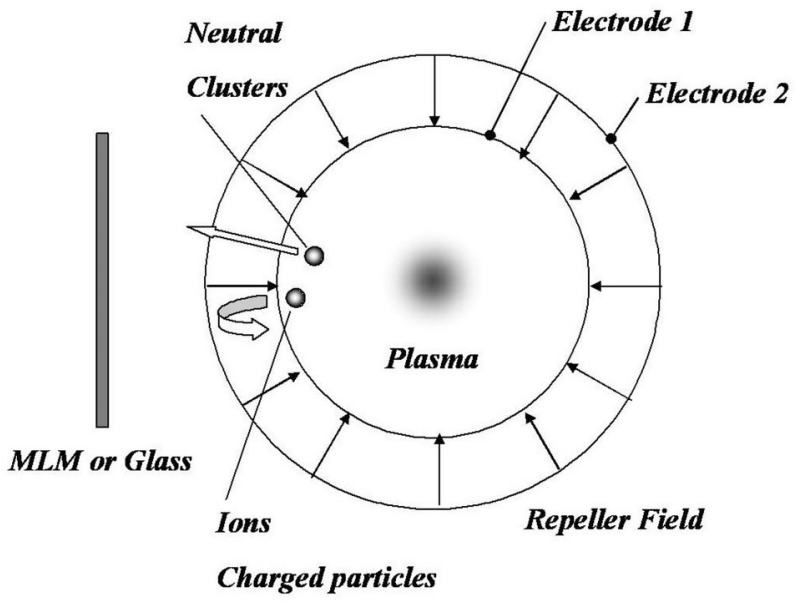

FIG. 11. Enchanced repeller field configuration.
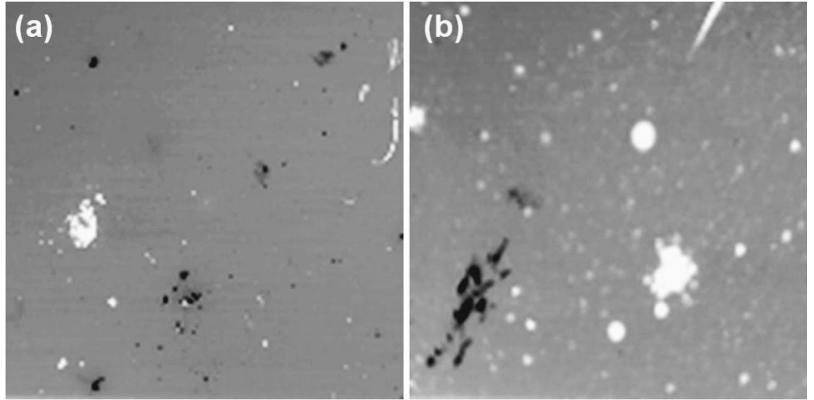

FIG. 12. (a) AEM backscattered image with repeller field and (b) without repeller field.

We are now testing a more advanced version of this repeller field concept. The concept is shown in Fig. 11. Ions or charged particles will be repelled by the electric field established by the electrodes. Neutral clusters, however, are not affected by the field. They can pass through the field and deposit on the MLM surface.

The initial experiment for the repeller field was carried out under the following conditions. The diameter of the inner electrode is $27 \mathrm{~mm}$ and its potential is maintained at $-100 \mathrm{~V}$. The outer electrode is $42 \mathrm{~mm}$ in diameter and it is at $300 \mathrm{~V}$ potential. MLM samples are placed $30 \mathrm{~mm}$ away from the plasma source and at $90^{\circ}$ of from the laser beam incident. The mirrors were exposed to the plasma source for a total of $3 \times 10^{4}$ laser shots. Figure 12 shows the AEM backscattered images of samples with and without the repeller field. The size of each image is $500 \mu \mathrm{m} \times 500 \mu \mathrm{m}$. The result shows significant reduction of tin deposits on the MLM surface when the repeller field was used. Further tests of this concept are in progress.

\section{CONCLUSION}

Our Sn-based droplet laser plasma source has provided an initial value for the conversion efficiency of $1.2 \%$, as measured with the Flying Circus device. We believe higher values are possible with better pulse and target coupling and greater control of the radiation dynamics. A combined experimental and theoretical approach therefore offers the best approach to designing the most optimum source. Debris from laser plasmas produced from mass-limited targets has been initially analyzed for the tin-doped target. An enchanced repeller field configuration is examined and has been shown to have a marked effect on the flow of debris from our tindoped target.

\section{ACKNOWLEDGMENTS}

The authors gratefully acknowledge useful discussions with Dr. Gerard O'Sullivan from University College, Dublin, the technical support of colleagues at LPL, Dr. Greg Shimkaveg, Somsak Teerawattenasook, Joshua Duncan, and Rob Bernath, and wish to thank Dr. David Attwood and Dr. Eric Gullickson from CXRO for multilayer mirrors. This work was partially supported by JMAR Technologies Inc., and the State of Florida. 
Presented at the 47th International Conference on Electron, Ion, and Photon Beam Technology and Nanofabrication, Tampa, FL, 27-30 May 2003.

${ }^{1}$ V. Y. Banine, J. P. H. Benschop, and H. G. C. Werij, Microelectron. Eng. 53, 681 (2000).

${ }^{2}$ C. Gwyn, D. Attwood, and D. Sweeney, J. Vac. Sci. Technol. B 16, 3142 (1998).

${ }^{3}$ D. A. Tichenor et al., Opt. Lett. 16, 557 (1991).

${ }^{4}$ B. A. M. Hansson, L. Rymell, M. Berglund, and H. M. Hertz, Microelectron. Eng. 53, 667 (2000).

${ }^{5}$ D. Moyer, presented at Sematech Workshop on EUVL Source Development, San Jose, 2 March 2001 (unpublished).

${ }^{6}$ F. Jin, K. Gabel, M. Richardson, M. Kado, A. F. Vassiliev, and D. Salzmann, Proc. SPIE 2015, 151 (1993).

${ }^{7}$ M. Richardson, D. Torres, C. DePriest, F. Jin, and G. Shimkaveg, Opt. Commun. 145, 109 (1998).

${ }^{8}$ G. Schriever, M. Richardson, and E. Turcu (unpublished).

${ }^{9}$ E. Turcu, H. Rieger, M. Powers, M. Richardson, and C. Keyser, presented at Sematech Workshop on EUVL Source Development, Matsue, Japan, 2001 (unpublished).

${ }^{10}$ First mentioned in a report by JMAR Research Corp. at the EUVL Source Workshop, Santa Clara, CA, 2 March 2001.

${ }^{11} \mathrm{M}$. Richardson, patent pending.
${ }^{12}$ JMAR laser, diode-pumped, $5000 \mathrm{~W}, 100 \mathrm{kHz}$

${ }^{13}$ TRW laser, diode-pumped, Nd:YAG, $4500 \mathrm{~W}, 5 \mathrm{kHz}$.

${ }^{14}$ M. Richardson and F. Jin, Topical Meeting EUV Lithography, Sept. 1994, pp. 41-43.

${ }^{15}$ F. Jin and M. Richardson, Topical Meeting EUV Lithography, Sept. 1994, pp. 88-91.

${ }^{16}$ F. Jin, M. Richardson, G. Shimkaveg, and D. Torres, Proc. SPIE 2523, 81 (1995).

${ }^{17}$ Concave diffraction grating $(R=5650 \mathrm{~mm}$, size $26 \mathrm{~mm} \times 46 \mathrm{~mm})$ model: 001-0266 from HITACHI.

${ }^{18}$ W. Schwanda, K. Eidmann, and M. C. Richardson, J. X-Ray Sci. Technol. 4, 8 (1993).

${ }^{19}$ R. Stuik, F. Scholze, J. Tummler, and F. Bijkerk, Nucl. Instrum. Methods Phys. Res. A 429, 305 (2002).

${ }^{20}$ AXUV Series detectors from IRD, Inc. (US).

${ }^{21} \mathrm{X}$-ray CCD camera model: MTE/CCD-1024-SB from Princeton Instrument.

${ }^{22}$ X-ray CCD camera model: PI-SX:512 from Princeton Instrument.

${ }^{23}$ G. O'Sullivan and R. Faulkner, Opt. Eng. 33, 3978 (1994).

${ }^{24}$ P. A. Rodgers, A. M. Rogoyski, and S. J. Rose, MED101: A laser-plasma simulation code. User Guide (Appleton, Rutherford, NJ, 1989).

${ }^{25}$ G. Shriever, M. Richardson, and E. Turcu, Proc. CLEO 2000, p. 393

${ }^{26}$ M. Richardson and G. Schriever, U.S. Patent No. 6,377,651 (2002). 